\title{
Para transitas Public Transportation Mode in Imphal
}

\author{
Dr. M. Ali Ahmed (Author) ${ }^{1}$ Waikhom Victory (Co-Author) ${ }^{2}$ \\ ${ }^{1,2}$ Associate Professor, Research Scholar Civil Engineering Deptt, NIT, Silchar, Assam- 788010
}

\begin{abstract}
Paratransit system consists of small passenger capacity vehicles operate on flexible routing and scheduling or fixed routing and flexible scheduling according to the usage of the trip makers. In Indian condition, paratransit plays an important role for the urban passenger transportation, particularly in the small and medium size cities. Imphal city has been selected in this study. Paratransit modes are the only means of public transportation system in Imphal. The study gives the detail information about the urban transit scenario of Imphal city. There are four major types of paratransit modes operating in the study area mainly, cycle-rickshaws, auto-rickshaws, tata magic and maruti van.The characteristics of each mode have been established by conducting different surveys such as modal split, vehicular occupancy and operator survey. The survey was carried out on important roads distributed all over the city. The percentage share of paratransit in terms of urban passenger movement has been found out with respect to all the modes. The auto-rickshaw is the most popular mode of paratransit having maximum share in terms of numbers and occupancy rate. The approach to transportation system is to focus not just on increasing vehicle movement, but on improving paratransit modes in the city. Predefined stoppage, parking for paratransit modes are essential to have better and timely service of the paratransit.
\end{abstract}

Keywords:modal split, operator survey, par transit, vehicular occupancy.

\section{Introduction}

Paratransi tplays an important role in the Imphal urban area. Major four types of paratransit modes are plying in the study area - cycle rickshaw, auto rickshaw, tata magic, maruti vans in the city to provide the needs of transportation services to the urbanites. Among these, auto rickshaw has the highest percentage share of occupants with respect to all the modes. The uses of cycle rickshaw is decreasing day by day as it is based on human energy and used for short distance services. Tata magic is another mode for the passengers for long trips. Taxi service and buses have less significant role in the city. In this paper, four major paratransit modes have been discussed. A special focus on the paratransit operators have been made through operator survey to know the socio - cultural characteristics of the operators, infrastructure facilities and service facilities of the operators. Paratransit not only provides the ease of movement from one place to another but it also generates a considerable amount of employment opportunities to the unemployed youths.

\subsection{IMPHAL}

Imphal is the Capital city of Manipur and it is located at the longitude $93^{\circ} 57^{\prime} \mathrm{E}$ and latitude $24^{\circ} 50^{\prime} \mathrm{N}$. The average height above the Mean Sea Level is $790 \mathrm{~m}$. The State has a very poor road communication facility. Highways or roads are regarded as arteries and veins of a State which are essential for its overall growth. The major functional railway head linking Manipur with the rest of India is at Dimapur town of Nagaland State which is $215 \mathrm{~km}$ away from Imphal. A rail head has been extended from Silchar to Jiribam. It covers only $1.5 \mathrm{~km}$ of railway line over the state of Manipur. Manipur has air links with other different states. The states have a very poor road communication facility. The main artery of communication is the $325 \mathrm{~km}$ long National Highway No. 39connecting Imphal with Dimapur in the neighbouring state of Nagaland. From Imphal it runs in the south east for another $110 \mathrm{~km}$ to the International border town of Moreh on the Indo-Myanmar border. Another road is the $225 \mathrm{~km}$ long National Highway No. 53, connecting Imphal with Silchar in Assam via Jiribam on the western fringe of the Manipur. [2]

\subsection{DEFINITION}

\section{Para transit}

Paratransit is urban passenger transportation service operating on public streets and highways in mixed traffic provided by private or public operators. [1] It is an alternative mode of flexible passenger transportation. The significant features of paratransit system are their flexibility and door to door service. Moreover, paratransit service offers mobility especially for the trip makers who do not own or have access to private vehicles. These people entirely depend on public transport for their daily movements, but in many occasions public transport are unreliable and inadequate. For this reason, they use paratransit services for their daily movements as it provides a bewildering array of transport modes bridging the gap between public transit and private transit. The goal of the paratransit service is to ensure that all people have access to transit to meet basic mobility needs. 


\subsection{CLASSIFICATION}

Paratransit modes can be classified in various forms according to its type of usage, ownership of vehicles or system, service types depending on the area where it operates. The paratransit modes are classified into following four major groups[4]:

- Type of usage: The paratransit services may be availed by different groups of users such as (a) fixed personalized mode of transportation (eg. Car rental and carpools); (b) semi publicparatransit (eg. Vanpools and subscription buses); (c) public (regular) paratransit (eg. Autorickshaw, cycle rickshaw, tata magic). In Imphal, public paratransit and some part of semi publicparatransit are available.

- Ownership of vehicles or system: Paratransit vehicles may be owned and service provided by an organization unrelated to transportation (factory, school), or by an individual who operates the vehicle (auto-rickshaw or cycle-rickshaw operator) or by an individual who does not operate but lease it out to the operator (owner) or by an agency (taxi company or tourist agency). The leased operator and owner operators are available in Imphal.

- Service type by routing: Generally, paratransit modes provide door- to-door services such as taxi, autorickshaw and cycle rickshaw. Sometimes they adjust the service partially to the user's destination (feeder service to airport, bus terminal). A third group of mode has fixed routes but not fixed schedule (shared travel mode auto-rickshaw service). It is also available in Imphal.

- Method of getting service: Users may have paratransit service available at fixed parking lots (autorickshaw, cycle-rickshaw) or their trips may be pre-arranged(subscription paratransits) or they obtain it by hailing the vehicle on street sides, or calling it by telephone from the travel agencies. It is not available in Imphal city.

In Imphal, paratransit operates in variable time and fixed space (shared mode service) and variable space and variable time (door- to- door service). It depicts that paratransit serves both variable schedule and fixed route as well as flexible schedule and flexible route. From the Fig.1, it indicates that auto-rickshaw, cycle- rickshaw, tata magic and van serves as a paratransit modes in the city.

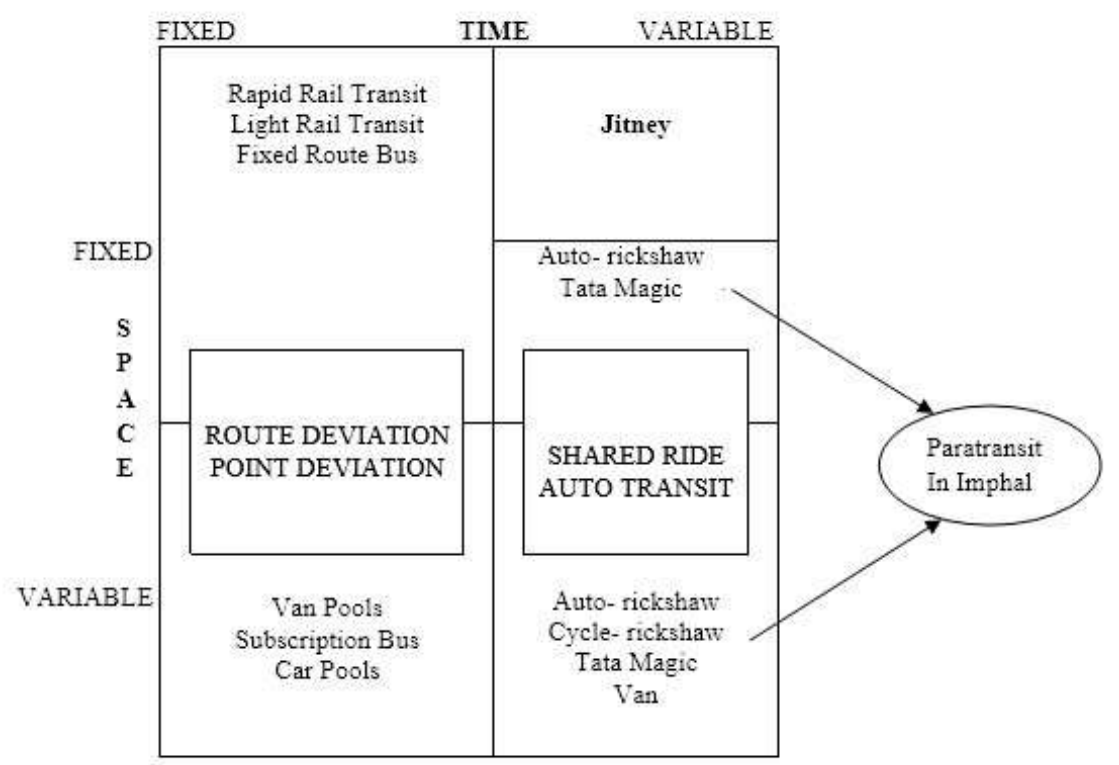

Fig 1: Temporal Spatial Characteristics of Urban Transportation Alternatives of Imphal

\subsection{PUBLIC TRANSIT}

Public transportation or transit includes multiple occupancy vehicle services designed to transport passengers on local and regional routes. Itis a shared passenger transportation service which is available for use by the trip makers, as distinct from modes such as taxicab, car pooling or hired buses which are not shared. It includes buses, trolleybuses, trams and trains, rapid transit. 


\section{Para transits In Imphal}

Four major types of paratransits are operating in the Imphal urban area and include cycle- rickshaw, auto- rickshaw, tata magic and maruti van. It is described below:

\subsection{CYCLE-RICKSHAW}

Cycle- rickshaw of two seated capacity is plying in Imphal city and is mainly used for the short trips for door to door service, shopping trips, etc. It is the slowest operating paratransit vehicle in the city and hence it causes congestion in the mixed operating traffic. But, it is the only vehicle which is easily maneuverable and non- polluting in the city.

\subsection{AUTO-RICKSHAW}

It is the predominantparatransit vehicle operating in the city. The maximum numbers of passengers are transported by the auto-rickshaw in the Imphal city. In Imphal, predominantly six seater diesel operated auto-rickshaws are found. The vehicle hasthe engine capacities of $416 \mathrm{CC}$ [5]. They are mainly used as a public transportation mode on shared basis, many a times they are also used for door-to- door services such as feeder trips, social and recreational trips, etc.

\subsection{TATA MAGIC}

The eight seatertata magic with 702CC [5] engine capacity operates on diesel fuel is operated in Imphal city. It is now widely used to transport passengers from the greater Imphal areas. The vehicle is mainly used for long distance regional trips for inter- district passenger transportation. Due to this, the urbanites do not prefer the mode for local transportation.

\subsection{MARUTI VAN}

Maruti vans are servicing as taxis in Imphal. Most of these vehicles are used in school services for students as vanpools. Taxi service is not popular in Imphal. It is used for specialized trips such as feeder trips to airport, trips made by tourist and some occasional trips. It has its own engine capacity of $796 \mathrm{CC}$ and its seat capacity of seven [6].

\section{Public Transit In Imphal}

Public transit is a service which provides basic mobility for those who are not able to provide their own private transportation. In Imphal, there is no conventional public transit for the passenger transportation services. Therefore, the paratransit filled up the gap of public transits and serves as a public transportation services in the Imphal. It is the only intermediate public transit services for the urbanites.

\section{Survey And Analysis}

Three types of survey were conducted modal split survey, vehicular occupancy survey and operator survey. Modal split survey was conducted to know the number of modes available in a particular zone of the city. The survey has been conducted for each one hour in different spots and repeated for 3 days in each spot and the numbers of vehicles were counted. Vehicular occupancy survey was also conducted to find out the average number of passengers carried by different modes. The survey was carried out on important roads distributed all over the city. Each type of mode was observed independently on a road section and number of passengers carried by the mode type was recorded. Certain specific places were taken like market area, local roads, major roads, minor roads, important public places to study the usage of paratransit modes and its variation. From the survey data, it indicates that among the paratransit, auto-rickshaw has maximum share and tata magic has least share as compared to other paratransit modes available in the city. It reveals that urbanites prefer auto-rickshaw as a main paratransit service for movements in the city.

After analyzing the modal split and vehicular occupancy survey, the total percentage share of paratransit in terms of occupants were found out and shown in figure 2 and 3. It is observed from the figure that the paratransit has $31 \%$ share among the other modes. However, within the paratransit auto-rickshaw has the maximum percentage share of $69 \%$, tata magic $16 \%$, van $10 \%$ and cycle-rickshaw of $5 \%$. 
घ Paratransit $\quad$ Private $\quad$ Other

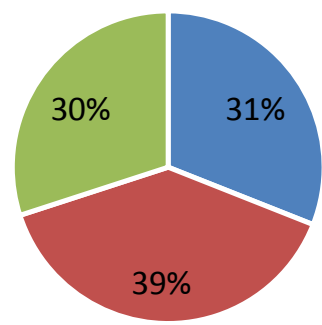

Figure.2. Percantage share of occupants within all modes at city

\section{- Auto Rickshaw - Cycle Rickshaw \\ - Tata Magic $\quad$ Van}

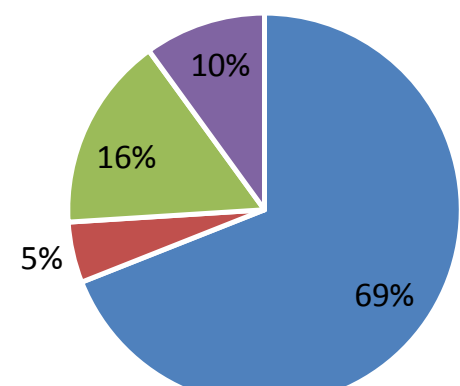

Figure.3. Percentage share of occupants within paratransit modes at

Paratransit operator survey has been conducted to understand the socio- cultural status of the paratransit operators, service and infrastructure facilities. The data were directly collected from the paratransit operators at their parking lots and garages where the operators were resting or waiting for the passengers. A set of questionnaire has been asked to know the characteristics of the operators. A sample size of 119 operators was collected and analysis has been done. Due to the time constraint, large number of data could not be collected. However, attempt has been made to collect the representative sample for each category of survey.In socio- cultural characteristics; a set of questionnaire was asked to the operator which includes the residential status, family conditions and their educational qualifications. Infrastructure facilities and service facilities were also asked to the operators to know the present scenario of the operators. By mere study of the surveyed data shown in table 1, depicts that the maximum numbers of the operators are found in the age group between 20 to 30 years and the percentage is found to be 30 percent among others. It has been observed that 29.42 percent of operators were the age group of 31 to 40 . The age groups of 41 to 50 and 51 to 60 have the percentage of 25.22 and 14.51 respectively. Only 0.85 percent has been found in the ages between 61 to 70 years. The literacy percentage of the operators is 100 percent and there are no illiterate operators. Most of the operators have their own vehicles. A very few operators used leased vehicles and migrated operators are also a very few in number. Among the operators 1.69 percent of operators are found post-graduates, 8 percent are under-graduates, 16 percent are matriculates and 54 percent are undermatriculate. Further, it is observed that 70 percent of the total operators are lone income earners in their families and 20 percent and 10 percent respectively are the double and triple income earners for their families. Only 1.68 percent of the operators are migrated from the other district and remaining 98.31 percent are original resident. For infrastructure facilities, some of the routes have no definite parking lots. Operators park their vehicles in a suitable place without having any facilities such as sheds, toilets, hotels, etc. However, parking areas in the city has been reserved by the authority of the state government without giving any facilities to the operators. The socio-cultural characteristics of the operator are in table below.

Table.1 Socio-cultural Characteristics of the paratransit operator in Imphal Urban Area

\begin{tabular}{|c|c|}
\hline Particulars & Percentage \\
\hline Age group in year: & \\
\hline $\begin{array}{l}20-30 \mathrm{yrs} \\
31-40 \mathrm{yrs} \\
41-50 \mathrm{yrs} \\
52-60 \mathrm{yrs} \\
61-70 \mathrm{yrs}\end{array}$ & $\begin{array}{c}30 \% \\
29.42 \% \\
25.22 \% \\
14.51 \% \\
0.85 \%\end{array}$ \\
\hline Educational qualificati & \\
\hline
\end{tabular}




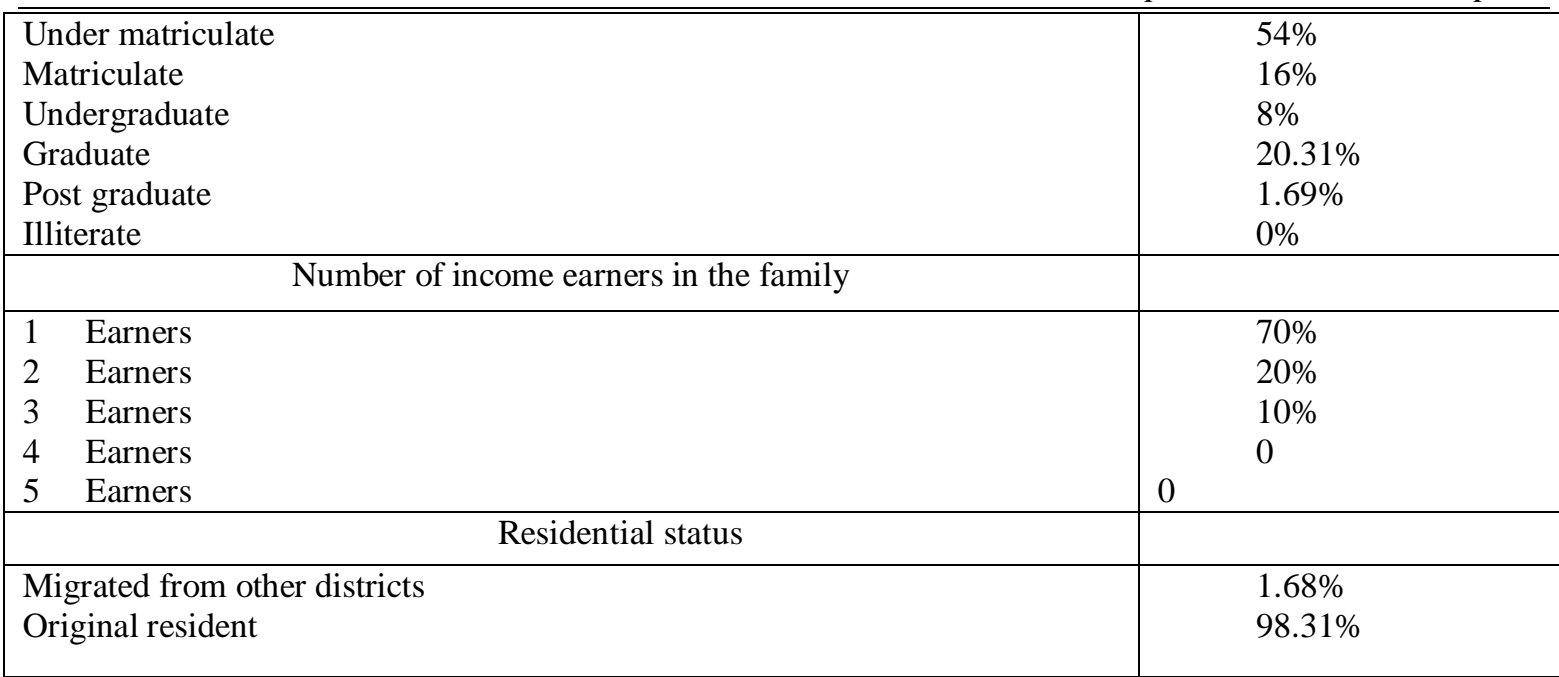

\section{RECOMMENDATIONS}

It is evident from the study that the paratransit modes have been used as public transit mode in the small and medium sized cities particularly in the north- eastern region of India. However, it is observed that paratransit modes are creating congestion in the urban street may be because of its slow speed, overcrowding of passengers, unsystematic parking policy, etc. Therefore, the following recommendations may be made to improve the services of the paratransit.

- Pre- defined stoppages to pick up and alight passengers.

- The maximum number of passengers carried should be less than or equal to the capacity of the vehicle.

- Auto-rickshaw may not be permitted further to reduce the noise pollution.

- A counter for collecting tickets for reserved taxies to be used by the passengers should be made.

- Separate lanes may be provided for the slow moving paratransits like cycle rickshaw as it causes more traffic jams.

- The old auto- rickshaw may be removed from the city for pollution control.

\section{Conclusion}

It is concluded from the study that the small and medium sized cities in Indian conditions, the paratransit plays an important role in urban passenger transportation. In Imphal, paratransits are used as a public transportation as it provides the basic transportation needs of the urbanites. It is the gap filler between the private transits and other conventional transits. They are the only public transportation mode operating in the city. The study has also shown that the paratransit operators are literate and they generate large scale of employment to the people. For better services, it is required to provide more facilities to the operators in terms of parking lot, garages, etc. So, the planners, engineers and policy makers should illustrate the activities in the context of some of the transportation modes in current use. Several steps can take up by analyzing the present scenarios. The actions should be made to ensure the efficient use of paratransit services. Improvement of transit service and internal management efficiency is highly necessary for future movements in the city as well as in the urban areas.

Books

\section{References}

[1]. Vuchic V.R," Paratransit and Specialisedmodes”, Urban Public Transportation: System and technology, Prentice Hall, 1979

[2]. Town Directory, Census of Manipur 2001

Journal

[3] Dr.M.AliAhmed; Socio - economic status of paratransit operator in the city of Assam, ITPI Journal, 2008 , Pp 21- 27.

Thesis

[4] Dr.M.AliAhmed; Utilities of Paratransit Modes in the Cities of Assam, India, Doctoral dissertation, Department of Architecture and Regional planning, IIT Kharagpur, 2008.

Link

[5] https://autos.maxabout.com

[6] www.made-from-india.com 